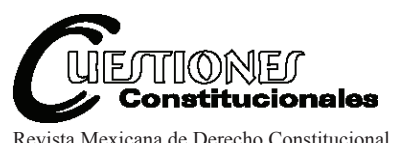

Revista Mexicana de Derecho Constitucional Núm. 38, enero-junio 2018

\title{
PROPUESTA DE TRES REFORMAS CONSTITUCIONALES PARA MEJORAR LA FISCALIZACIÓN DE RECURSOS PÚBLICOS
}

\author{
PROPOSAL FOR THREE CONSTITUTIONAL REFORMS \\ TO IMPROVE THE AUDIT OF PUBLIC RESOURCES
}

\begin{abstract}
RESUMEN: Este documento hace un recuento de los alcances más importantes de las dos reformas constitucionales del 26 y 27 de mayo de 2015 que modificaron los artículos 79, 116 y 122 en relación con la fiscalización de recursos públicos, para después centrarse en el análisis de las inconsistencias generadas por estas reformas, en cuanto a los principios rectores de la labor fiscalizadora de la Auditoría Superior de la Federación y las auditorías subnacionales. Mi hipótesis es que ambas reformas generaron una contradicción entre lo que establecen dichos artículos constitucionales respecto a los principios de anualidad y posterioridad. Además, desaprovecharon la oportunidad para resolver una añeja incoherencia respecto del principio de definitividad. Este artículo concluye proponiendo tres reformas a la Constitución que le darán coherencia, balance y sobre todo certidumbre jurídica tanto a los entes fiscalizados como a los entes fiscalizadores.
\end{abstract}

Palabras clave: Auditoría Superior de la Federación, reforma constitucional, fiscalización, recursos públicos, principios, anualidad, posterioridad, definitividad.

\section{Yahir AcosTA*}

ABSTRACT: This document reviews the recent ammendments of Articles 79, 116 and 122 of the Mexican Constitution. It identifies and evaluates the inconsistencies generated by the reforms of May 26 and 27 of 2015 regarding the guiding principles of the audit work performed by the Federal Audit Office (Auditoría Superior de la Federación) and subnational audit offices. My hypothesis is that both reforms have created a contradiction between the above mentioned articles in respect to the principles of annuality and posteriority. In addition, these reforms also missed the opportunity to resolve a longstanding inconsistency with the principle of definiteness. This article concludes putting formard a proposal for three reforms to Articles 79, 116 and 122, respectively, which will give more coherence and balance to the Mexican Constitution, and above all, will give more legal certainty to both audited entities and auditing bodies.

Keywords: Federal Audit Office, Ammendment, Mexican Constitution, Guiding Principles, Annuality, Posteriority, Definiteness.

* Licenciado en derecho por el ITAM, máster en derecho (con honores) por la Queen Mary, University of London, y doctorando en derecho por la UNAM, yair.acosta@ethos. org.mx. 
Sumario: I. Introducción. II. Contexto y objetivo de las dos reformas constitucionales de 2015. III. Principio de definitividad: artículo 79 vs. artículos 116 y 122. IV. Principios de anualidad y posterioridad: artículo 79 vs. artículo 79. V. Alcance "retrorrevisor" de la función fiscalizadora. VI. Conclusiones.

\section{INTRODUCCIÓN}

La fiscalización de recursos públicos es una labor fundamental para la rendición de cuentas a la ciudadanía, y es uno de los pilares en los que está cimentado el Sistema Nacional Anticorrupción (SNA). A nivel constitucional, la fiscalización de recursos públicos está regulada principalmente por los artículos 79, 116 y 122, por lo que no es casualidad que estos tres artículos hayan sido reformados en el contexto del nacimiento del SNA. ${ }^{1}$

Las dos reformas constitucionales que modificaron a los artículos 79, 116 y 122 se publicaron con un día de diferencia, pues una se realizó el 26 y la otra el 27 de mayo de 2015. Así las cosas, puede decirse que el movimiento reformista fue prácticamente simultáneo. Por esta razón, los dos esfuerzos reformistas apuntaban en la misma dirección: ampliar y mejorar la fiscalización de recursos públicos llevada a cabo por la Auditoría Superior de la Federación (ASF), las entidades fiscalizadoras estatales y de la Ciudad de México (en adelante, me referiré a estas dos últimas como las "auditorías subnacionales").

La reforma del 27 de mayo de 2015 delineó la nueva cara de los principios rectores de la labor fiscalizadora de la ASF y las auditorías subnacionales. Este documento de investigación centra el análisis en las posibles inconsistencias generadas por esta reforma. El problema que he identificado es que la reforma mencionada generó una contradicción entre lo que dicen los artículos 79, 116 y 122 constitucionales respecto a los principios de anualidad y posterioridad. Además, desaprovechó la oportunidad para

1 Estas y otras reformas constitucionales provocarían eventualmente la publicación de cuatro nuevas leyes y la reforma de tres, que forman parte del SNA. Secretaría de la Función Pública (2016), Acciones y Programas, Sistema Nacional Anticorrupción, Leyes Secundarias del Sistema Nacional Anticorrupción, disponibles en: http://www.gob.mx/ sfp/acciones-y-programas/leyes-secundarias-del-sistema-nacional-anticorrupcion (consultada el 1o. de septiembre de 2017). 
resolver una añeja incoherencia respecto del principio de definitividad. El significado y alcance de estos principios será ofrecido en las secciones II y III de este documento.

En todo caso, me parece que las inconsistencias identificadas en este documento de investigación pueden y deben enmendarse a la brevedad, pues de lo contrario entorpecerán o demorarán indebidamente la labor de la ASF y/o de las auditorías subnacionales, en la fiscalización de recursos públicos.

En vista de lo anterior, en este documento presentaré tres propuestas de reformas constitucionales con el objetivo de dar coherencia a los principios rectores de la labor fiscalizadora, tanto a nivel federal como local. Para esto, primero comenzaré dando una breve explicación del contexto de las dos reformas constitucionales de 2015, para después explicar la problemática del texto de los artículos 79, 116 y 122; finalmente presentaré las propuestas de reforma respectivas.

\section{CONTEXTO Y OBJETIVO DE LAS DOS REFORMAS CONSTITUCIONALES DE 2015}

Las modificaciones a los artículos 79, 116 y 122 constitucionales se dieron en el contexto de dos grandes reformas simultáneas, las cuales apuntaban en la misma dirección: ampliar el universo fiscalizable y fortalecer las capacidades de investigación de la ASF y las auditorías subnacionales en la fiscalización de recursos públicos. ${ }^{2}$

Aunque el objeto de este documento centra su análisis en los principios rectores de la reforma constitucional del 27 de mayo de 2015, considero necesario comenzar explicando el contexto y alcance de la reforma del 26 de mayo del mismo año. Esto debido a que los principios rectores de la fiscalización guiarán el actuar de la ASF sobre un nuevo universo fiscalizable, significativamente más grande, delineado por las dos reformas mencionadas.

2 Al final de este documento se agrega una tabla para facilitar la visualización de la comparación de los cambios generados por las reformas que son analizadas en este trabajo. Véase tabla 2. "Matriz histórica (abreviada) de los artículos 79, 116 y 122 constitucionales". También se puede consultar una matriz histórica que refleja la totalidad de los cambios entre los artículos mencionados, para lo cual véase Acosta, Yahir y Gonzzali, Evelyn, "Matriz histórica de los artículos 79, 116 y 122 constitucionales", disponible en: https://docs.google.com/document/d/1RurjHat-St8QN0JDzdsalUiyLctNTzKCyl-n9ZC bxaY/edit? usp=sharing (consultada el 1o. de septiembre de 2017). 
La reforma constitucional del 26 de mayo del 2015 modificó los artículos 79 y 116. Para efectos prácticos, este autor identifica a este impulso reformista como "la reforma de la fiscalización de la deuda pública", porque principalmente amplió el alcance para abarcar la fiscalización de la deuda. Sin embargo, debe decirse que esta reforma también está estrechamente ligada con el combate a la corrupción. Por esta razón, la reforma se generó en el contexto de la creación del SNA. La relación directa entre deuda pública y corrupción es un tema muy relevante, pero no elaboro comentarios al respecto porque no es el objetivo de este documento. Baste decir que esta relación ha sido analizada y comprobada tanto a nivel internacional como nacional. ${ }^{3}$

La "reforma de la fiscalización de la deuda pública" del 26 de mayo de 2015 de los artículos 79 y 116, es relevante porque amplió los alcances de la fiscalización que puede hacer la ASF, tanto del gasto federal como del gasto federalizado. ${ }^{4}$ Primero, respecto del gasto federal la amplió porque la

3 A nivel nacional encontramos un ejemplo Astudillo Moya, Marcela et al., "La transparencia en la deuda estatal como mecanismo para prevenir la corrupción", Premio Nacional de Finanzas Públicas 2016, Centro de Estudios de Finanzas Públicas, disponible en http://www.cefp.gob.mx/formulario/Trabajo_8a.pdf (consultada el 1o. de septiembre de 2017). A nivel internacional Cooray, Dzhumashev y Schneider utilizan un modelo econométrico entre 1996 y 2012 que engloba a 126 países (incluido México) con el que comprueban empíricamente que un aumento en la corrupción implica un aumento en la deuda pública. Cooray, Arusha et al., "How does Corruption Affect Public Debt? An Empirical Analysis", World Development, vol. 90, febrero de 2017, pp. 115-127. Véase Lambsdorff, Johann Graf, "Causes and Consequences of Corruption: What Do We Know from a Cross-Section of Countries?", en Rose-Ackerman, Susan (ed.), International Handbook on the Economics of Corruption, Cheltenham-Northampton, Elgar, 2006, pp. 3-51.

4 "El gasto federalizado o descentralizado se integra por los recursos que el gobierno federal transfiere a los estados y municipios a través de las participaciones y aportaciones federales, los apoyos para las entidades federativas (PAFEF) y los convenios de descentralización. Estos recursos provenientes de la Federación son empleados por los gobiernos estatales para complementar sus respectivos gastos en educación, salud, infraestructura social, seguridad pública, sistema de pensiones, deuda pública, entre otros.

El gasto federalizado se integra de los siguientes ramos generales del Presupuesto de Egresos de la Federación (PEF): el 28: participaciones federales; el 33: aportaciones federales; el 25: previsiones y aportaciones para los sistemas de educación básica, normal, tecnológica y de adultos; el ramo 39: programa de apoyos federales para las entidades federativas; y los convenios de descentralización”. Cámara de Diputados, Servicio de Investigación y Análisis, disponible en: http://www.diputados.gob.mx/sia/intranet/siadec-iss-07-05/anualizado/intro.htm (consultada el 1o. de septiembre de 2017). 
reforma a la fracción I del artículo 79 añadió que la fiscalización de la ASF no sólo abarca a los ingresos y a los egresos de los entes públicos federales, sino también a la deuda contratada por éstos, y de ser aplicable, incluso a las garantías que haya otorgado el "gobierno federal respecto a empréstitos de los estados y municipios". 5

En segundo lugar, la adición al segundo párrafo de la fracción I del artículo 79 amplió la fiscalización que la ASF puede hacer del gasto federalizado. Sobre este punto vale la pena aclarar que si bien no se incluyó expresamente la mención a la deuda pública contratada por estados y municipios, la ASF sí podrá fiscalizar directamente el destino y ejercicio de los recursos provenientes de los créditos obtenidos por los gobiernos locales cuando "cuenten con la garantía de la Federación", por ejemplo, cuando se hayan obtenido los créditos otorgando como garantía las aportaciones federales. ${ }^{6}$

Con la misma determinación, la "reforma de la fiscalización de la deuda pública" del 26 de mayo de 2015 modificó el artículo 116 constitucional, también buscando ampliar las facultades de las entidades estatales de fiscalización al añadir una última oración al sexto párrafo de su fracción II: "Asimismo, deberán fiscalizar las acciones de estados y municipios en materia de fondos, recursos locales y deuda pública".?

5 Véase pfo. 1o., frac. I, artículo 79, Diario Oficial de la Federación, 26 de mayo de 2015, establece una de las facultades de la ASF: "I. Fiscalizar en forma posterior los ingresos, egresos y deuda [pública federal]; las garantías que, en su caso, otorgue el gobierno federal respecto a empréstitos de los estados y municipios; el manejo, la custodia y la aplicación de fondos y recursos de los poderes de la Unión y de los entes públicos federales, así como realizar auditorías sobre el desempeño en el cumplimiento de los objetivos contenidos en los programas federales, a través de los informes que se rendirán en los términos que disponga la ley". Las cursivas son añadidas por este autor, e indican que esa parte del texto fue adicionado por la reforma del 26 de mayo de 2015.

6 Véase pfo. 2o. frac. I, artículo 79, Diario Oficial de la Federación, 26 de mayo de 2015. "También fiscalizará directamente los recursos federales que administren o ejerzan los estados, los municipios, el Distrito Federal y los órganos político-administrativos de sus demarcaciones territoriales, con excepción de las participaciones federales. En el caso de los estados y los municipios cuyos empréstitos cuenten con la garantía de la Federación, fiscalizará el destino y ejercicio de los recursos correspondientes que hayan realizado los gobiernos locales". Las cursivas son añadidas por este autor, e indican que esa parte del texto fue adicionado por la reforma del 26 de mayo de 2015. Para comparar las diferentes versiones del texto de artículo 79, se sugiere seguir la indicación de la nota al pie número 2 de este documento.

7 Este marcado énfasis de la reforma de los artículos 79 y 116, 26 de mayo de 2015 por regular cuestiones relacionadas con la deuda pública provocaría que un año después 
La segunda reforma constitucional que se aborda en este documento de investigación es la del 27 de mayo de 2015, la cual modificó el texto constitucional de los artículos 79, 116 y 122. Para efectos prácticos, este autor la identifica como "la reforma de la ASF", pues su vocación es la de crear nuevas reglas que determinan las formas y los tiempos en que la ASF puede realizar su función de fiscalización, así como los alcances del universo fiscalizable por la ASF. Esto tiene consecuencias cualitativas y cuantitativas.

Cuantitativamente, por su trascendencia debe mencionarse que se eliminaron seis palabras de la última frase del segundo párrafo de la fracción I del artículo 79: “con excepción de las participaciones federales". Esas seis palabras implicarán en 2017 un gasto de \$742,566’220,934 pesos, es decir, más de $15 \%$ del gasto público total para $2017 .{ }^{8} \mathrm{La}$ consecuencia práctica de borrar esa frase implica que la ASF ha aumentado de manera significativa el universo fiscalizable que ahora puede abarcar. ${ }^{9}$

Cualitativamente, la "reforma de la ASF" del 27 de mayo del 2015 tiene como uno de sus resultados más importantes haber delineado la nueva cara de los principios rectores de la labor fiscalizadora de la ASF, de las entidades fiscalizadoras estatales y de la Ciudad de México. Sin duda alguna, estos principios se aplicarán en todo el universo fiscalizable, incluido el ampliado tanto por la reforma del 26 como la del 27 de mayo de 2015.

El problema que he identificado es que parece haber una contradicción entre lo que dicen los artículos 79, 116 y 122 constitucionales respecto a los principios de anualidad, posterioridad y definitividad.

se publicara la importante Ley de Disciplina Financiera de las Entidades y Municipios, Diario Oficial de la Federación, 27 de abril de 2016.

8 Cálculo propio tomando como base que el gasto neto total presupuestado para 2017 será de \$4'888,892'500,000 pesos. Véase “Anexo 1. Gasto Neto Total” del Presupuesto de Egresos de la Federación, ramo 28: participaciones a entidades federativas y municipios (es decir, participaciones federales) \$742,566’220,934 pesos.

9 Además de las participaciones federales, el universo fiscalizable por la ASF también aumentó porque la reforma a ese mismo párrafo del artículo 79 aclaró que la fiscalización de la ASF sobre recursos federales incluye los destinados o ejercidos a través de fideicomisos privados, además de los fideicomisos públicos. 
Esta revista forma parte del acervo de la Biblioteca Jurídica Virtual del Instituto de Investigaciones Jurídicas de la UNAM

\section{PRINCIPIO DE DEFINITIVIDAD:}

ARTículo 79 VS. ARTículos 116 y 122

Las reformas del 26 de mayo del 2015 y del 27 de mayo del 2015 desaprovecharon la oportunidad para resolver una añeja incoherencia respecto del principio de definitividad. Digo añeja, porque esa incoherencia existe desde el 7 de mayo de 2008, fecha en que fue añadido el texto constitucional de los artículos 79, 116 y 122 con los principios rectores, incluido el de definitividad.

Antes de identificar dicha incoherencia, comenzaré explicando que existen diferentes interpretaciones respecto de lo que significa el principio de definitividad en la fiscalización de recursos públicos. Aunque no existen criterios jurisprudenciales, en la doctrina se encuentran dos posturas: la de Miguel Pérez López de $2010^{10}$ y la de Víctor Manuel Rocha Mercado de 2017. ${ }^{11}$ En mi opinión, aunque cada una tiene un matiz diferente, ${ }^{12}$ ambas reflejan que la intención del principio de definitividad es entregar seguridad y certeza jurídicas.

10 "Ligado con el principio de legalidad, tenemos que la función fiscalizadora debe ser completa, eficiente y exhaustiva, a fin de evitar expedientes abiertos, que puedan propiciar conflictos políticos y jurídicos intermitentes, por lo que las decisiones que asuma la Entidad de Fiscalización Superior sean definitivas, sin que el principio de definitividad sea óbice para que la Auditoría Superior emita las sanciones y formule las denuncias que correspondan", Pérez López, Miguel, "Gasto público, fiscalización y administración de recursos económicos públicos”, Revista Mexicana de Derecho Constitucional, México, núm. 22, enero-junio de 2010, pp. 203 y 204.

11 "Por cuanto hace al principio de definitividad, y tomando en cuenta el tercer párrafo del artículo 79, puede afirmarse que es un mandato dirigido a la Auditoría Superior de la Federación para que todos los informes que emita en el ejercicio de sus facultades se basen en la información definitiva que se presente en la Cuenta Pública anual". Rocha Mercado, Víctor Manuel, comentario al artículo 79 constitucional, Constitución Política de los Estados Unidos Mexicanos Comentada II, en Cossío Díaz, José Ramón (coord.), México, Tirant Lo Blanch, 2017, t. 2, p. 1293.

12 No es el objetivo de este documento hacer una disertación sobre estas dos posturas, sin embargo, me parece muy importante que alguien pueda retomar este tema en una futura investigación. En todo caso, creo que la decisión por adoptar un matiz u otro tiene que hacerse después de realizar una revisión profunda, de carácter holístico, de los cuatro principios (legalidad, definitividad, imparcialidad y confiabilidad) que actualmente aparecen en el artículo 79 constitucional y tomando como contexto la eliminación de los otros dos principios (posterioridad y anualidad), así como la adición de nuevos párrafos en el texto constitucional del artículo 79. En mi opinión, se trata de una compleja, delicada y extensa tarea porque muchos de estos principios están entrelazados. 
Habiendo dado una breve orientación sobre el contenido del principio de definitividad, ahora procederé a revisar lo que he identificado como un problema de equilibrio en el pacto federal para la fiscalización de recursos públicos. En mi opinión es claro que existe un desbalance en relación con este principio.

Por un lado, el párrafo segundo reformado del artículo 79 establece que uno de los principios de la función de fiscalización ejercida por la ASF será el principio de definitividad:

Artículo 79. La Auditoría Superior de la Federación de la Cámara de Diputados...

La función de fiscalización será ejercida conforme a los principios de legalidad, definitividad, imparcialidad y confiabilidad [cursivas añadidas].

En contraste, el principio de definitividad no es mencionado en los principios rectores de la función de fiscalización a nivel local contenidos en el artículo 116 fracción II párrafo 6o., el cual regula la fiscalización estatal:

Artículo $116 \ldots$ Los poderes de los estados se organizarán conforme a la Constitución de cada uno de ellos, con sujeción a las siguientes normas:

II...

Las legislaturas de los estados contarán con entidades estatales de fiscalización, las cuales serán órganos con autonomía técnica y de gestión en el ejercicio de sus atribuciones y para decidir sobre su organización interna, funcionamiento y resoluciones, en los términos que dispongan sus leyes. La función de fiscalización se desarrollará conforme a los principios de legalidad, imparcialidad y confiabilidad. Asimismo, deberán fiscalizar las acciones de estados y municipios en materia de fondos, recursos locales y deuda pública. Los informes de auditoría de las entidades estatales de fiscalización tendrán carácter público [cursivas añadidas].

También es contrastante la ausencia del principio de definitividad en el artículo 122, inciso A, fracción II, sexto párrafo, el cual regula la fiscalización en la Ciudad de México: ${ }^{13}$

13 Después de la reforma constitucional al artículo 122, del 27 de mayo de 2015, esta parte se encontraba en el inciso C, base primera, fracción V, inciso e). Sin embargo, esta ubicación cambió recientemente porque el artículo 122 fue restructurado, además de 
Artículo $122 \ldots$
A...
I...
II...

Asimismo, corresponde a la legislatura de la Ciudad de México revisar la cuenta pública del año anterior, por conducto de su entidad de fiscalización, la cual será un órgano con autonomía técnica y de gestión en el ejercicio de sus atribuciones, y para decidir sobre su organización interna, funcionamiento y resoluciones, en los términos que disponga su ley. $\mathrm{La}$ función de fiscalización se desarrollará conforme a los principios de legalidad, imparcialidad y confiabilidad [cursivas añadidas].

En vista de lo anterior, es evidente un desbalance respecto del principio de definitividad para la fiscalización a nivel local y federal, porque la Constitución federal no lo exige para las entidades estatales de fiscalización (artículo 116) ni para la Ciudad de México (artículo 122), pero sí lo exige a nivel federal (artículo 79). Por esta razón, se recomienda una reforma constitucional que equilibre la asimetría existente entre el artículo 79 en relación con los artículos 116 y 122.

\section{PRINCIPIOS DE ANUALIDAD Y POSTERIORIDAD: ARTículo 79 VS. ARTíCULO 79}

Como se ha explicado, el párrafo segundo reformado del artículo 79 establece cuáles son los principios de la fiscalización de la ASF. Además del principio de definitividad abordado en la sección anterior, también menciona a los principios de legalidad, imparcialidad y confiabilidad. La reforma del 27 de mayo del 2015 eliminó la mención en este párrafo a los principios de anualidad y posterioridad.

El problema es que a pesar de su eliminación, siguen existiendo referencias a esos principios, lo cual podría ser contradictorio. Antes de identificar estas posibles inconsistencias, comenzaré explicando qué son y cuál es el

reformado, en vista de la reciente reforma política que transformó al Distrito Federal en la Ciudad de México, Diario Oficial de la Federación, 5 de febrero de 2017. Por esta razón puede decirse que el nuevo artículo 122 espejea la estructura del 116, por lo menos en cuanto al tema de la fiscalización: no parece casualidad que ahora el artículo 122 regule el tema de los principios rectores de la fiscalización en la fracción II, pfo. 6o., así como el artículo 116 lo hace para los estados también en su fracción II, pfo. 6o. 
alcance de los principios de anualidad y posterioridad, respectivamente, para poder comprender las consecuencias jurídicas de su eliminación.

De acuerdo a un criterio de la SCJN de 2003, el principio de anualidad

constituye un límite a la facultad de revisión [de] la Auditoría Superior de la Federación, [por lo que] dicho ente no [tiene] la posibilidad jurídica de verificar los términos de programas gubernamentales realizados por los Poderes de la Unión en ejercicios anteriores al que constituye la materia de la verificación. ${ }^{14}$

\section{En 2004 la SCJN volvió a abordar el tema y estableció que el}

principio constitucional de anualidad que, como expresión del principio de seguridad jurídica, obliga a dicha autoridad a que circunscriba el objeto de la revisión del resultado de la cuenta de la hacienda pública federal a las actuaciones verificadas en el ejercicio anual auditado, sin perjuicio de las excepciones autorizadas constitucional o legalmente. ${ }^{15}$

Ciertamente, esos criterios de la SCJN no se sustentaron en el segundo párrafo del artículo 79, es decir, no se fundamentaron en el párrafo que contiene los principios rectores de la labor fiscalizadora de la ASF. Esto es así porque esos principios se incluyeron hasta 2008 en el texto constitucional. Por esta razón, la SCJN tenía que recurrir al artículo 74 fr. IV, que le da la facultad a la Cámara de Diputados para "Aprobar anualmente el Presupuesto de Egresos de la Federación”, para de ahí derivar el principio de anualidad en la revisión de la ASF de la cuenta pública. ${ }^{16}$

Así las cosas, puede definirse al principio de anualidad como el eje de la actuación de los entes fiscalizadores que los obliga a restringir su revisión exclusivamente a la del año fiscal auditado durante el cual se ejerce

14 Semanario Judicial de la Federación y su Gaceta, Novena Época, t. XXII, septiembre de 2005, tesis P./J. 98/2005, p. 888.

15 Semanario Judicial de la Federación y su Gaceta, Novena Época, t. XXII, agosto de 2005, tesis P. XXX/2005, p. 889.

16 El hecho que en 2003 y 2004 la SCJN tuviera que recurrir a malabares interpretativos para dar coherencia en la actuación de la ASF, dejó en evidencia una laguna jurídica constitucional muy relevante: los artículos 79, 116 y 122 no contenían principios rectores para la fiscalización de los recursos públicos. Esa laguna fue llenada el 7 de mayo de 2008, fecha en que fue añadido el texto constitucional respectivo para los artículos 79, 116 y 122 con los principios rectores. 
el presupuesto público, el cual, huelga decir, para México corresponde al año calendario.

Respecto al principio de posterioridad, debido a la relativamente reciente inserción (Diario Oficial de la Federación, 7 de mayo de 2008) de los principios rectores en el segundo párrafo del artículo 79 constitucional, no existen criterios jurisprudenciales que expliquen qué se entiende por este principio. Sin embargo, en una controversia constitucional la SCJN hizo alusión a la iniciativa de reforma constitucional de 2008 que incluyó como principios rectores el de "posterioridad, anualidad, legalidad, definitividad, imparcialidad y confiabilidad". A pesar de que la SCJN no interpretó el significado del principio de posterioridad, es posible hacerlo ahora interpretando a contrario sensu lo manifestado en la iniciativa de reforma constitucional de 2008. De esta forma, puede afirmarse que el principio de posterioridad prohíbe la revisión de la Cuenta Pública durante el ejercicio fiscal en curso. ${ }^{17}$ En otras palabras, el principio de posterioridad obliga a que la fiscalización se realice sólo cuando haya sido concluido el ejercicio fiscal que se quiere auditar. Esta definición coincide con otras que han sido ofrecidas por estudiosos de la materia. ${ }^{18}$

17 Véase voto particular que formuló el ministro José Fernando Franco González Salas en las controversias constitucionales 133/2008, 134/2008 y 135/2008, Semanario Judicial de la Federación y su Gaceta, Novena Época, t. XXXIII, marzo de 2011, disponible en: http://sjf.scjn.gob.mx/sjfsist/(F(xS70ZEAywGYwKxrXGWhR8z0vIhDpFB LSKcCv9rmCPPUweBeaJ2-FflM8ekZ3pJlp1rrqg9H9TEoM2HLIpMWlB7C9Uumkpdnb42p1R9xal54-fUA_D4s1Xp6mKj0GlWh1xeKNuAWdb7YHKcHJFoMgU0KpZSmBi$451 \mathrm{~F} 1$ E-kJ8L3oI1))/paginas/DetalleGeneralScroll.aspx? id $=40586 \&$ Clase $=$ VotosDetal leBL (consultada el 1o. de septiembre de 2017). "Sobre la diferenciación entre ambos tipos de procedimientos y el alcance de los principios de anualidad y posterioridad, destaca lo señalado en la iniciativa de reformas a estos preceptos constitucionales (7)" que, en lo conducente, refirió: "En relación con el último pfo. de la frac. I, artículo 79, se estima necesario realizar una precisión para aclarar los alcances de la reforma a dicha disposición realizada en el año 1999. En este sentido, en congruencia con la reforma de 1999 se propone precisar que la facultad de revisión prevista en el párrafo señalado es una excepción al principio de posterioridad en la fiscalización, lo cual implica que la Auditoría Superior de la Federación puede realizar revisiones durante el ejercicio fiscal en curso, en las situaciones excepcionales que señale la ley".

18 Pérez López, Miguel, "Gasto público...”, cit., p. 203. Por otro lado, la definición de Rocha Mercado sobre el principio de definitividad también puede verse como una expresión del principio de posterioridad, especialmente porque toma como contexto el tercer párrafo del artículo 79 constitucional (añadido por la reforma del 27 de mayo de 2015). Cfr. nota 10 . 
Como se ha explicado, la reforma constitucional del 27 de mayo de 2015 eliminó la mención en el párrafo segundo del artículo 79 a los principios de anualidad y posterioridad. ${ }^{19}$ La eliminación de estos dos principios se debió a que, en el contexto de la creación del Sistema Nacional Anticorrupción, se consideró que para mejorar la fiscalización de los recursos públicos tenían que cambiarse las reglas relacionadas con la anualidad y posterioridad de la labor de la ASF y de las auditorías locales. ${ }^{20}$

De esta forma, y en atención a los criterios jurisprudenciales que definen el principio de anualidad, la eliminación de este principio permite a la ASF revisar ejercicios anteriores al que constituye la materia de la verificación. Cabe preguntarse si existe un límite para esta revisión retroactiva. Este punto es abordado y respondido en la siguiente sección de este documento.

Respecto al principio de posterioridad, teniendo en cuenta la interpretación a contrario sensu presentada, puede decirse que la eliminación de este principio permite a la ASF que la fiscalización se realice en cualquier momento durante el ejercicio presupuestal del gasto. En la exposición de motivos de la "reforma de la ASF" incluso se utiliza el neoconcepto de una fiscalización en "tiempo real". ${ }^{21}$

Después de construir una definición para los principios de anualidad y posterioridad, este documento ha comenzado a ofrecer una posible explicación del alcance de su eliminación. Ahora es momento de identificar posibles incosistencias en el texto del artículo 79 constitucional.

Iniciaré apuntando que la reforma constitucional del 27 de mayo de 2015 eliminó de manera consistente los principios de anualidad y posterioridad en los artículos 116 y 122, es decir, no existe contradicción entre estos dos

19 También los eliminó de otros lugares del artículo 79. Por ejemplo, de su fracción I, pfos. 4o. y 5o. (que eliminaron anualidad y posterioridad, respectivamente). Además, el artículo 116, frac. II, pfo. 6o., eliminó ambos principios como rectores de las labores de las entidades estatales de fiscalización de las legislaturas de los estados. Para ubicar las coordenadas actuales de esta reforma relativas al artículo 122, véase la nota 12 de este documento.

20 Declaratoria de publicidad de los dictámenes de la Comisión de Puntos Constitucionales, con proyecto de decreto por el que se reforman y adicionan diversas disposiciones de la Constitución Política de los Estados Unidos Mexicanos, en materia de anticorrupción, Comisión de puntos constitucionales de la Cámara de Diputados, Gaceta Parlamentaria, núm. 4223-III, año XVIII, anexo III, 26 de febrero de 2015, pp. 20, 21, 46 y 47, diponible en: http://gaceta.diputados.gob.mx/PDF/62/2015/feb/20150226-III. $p d f$ (consultada el 1o. de septiembre de 2017).

21 Idem. 
artículos de cara al artículo 79. Hasta aquí no existe conflicto alguno. Sin embargo, el problema que he identificado es que parece haber una contradicción entre lo que dice el segundo párrafo del artículo 79 con otros párrafos del mismo artículo 79. Explico a continuación.

Puede argumentarse que existe una contradicción pues los subsecuentes párrafos del artículo 79 aluden a que tanto la posterioridad como la anualidad siguen rigiendo la fiscalización por parte de la ASF. En el primer caso, a pesar de haberse eliminado el principio de posterioridad por la reforma del 27 de mayo de 2015, la posterioridad se dejó expresamente mencionada en la fracción I del artículo 79, que señala: "La Auditoría Superior de la Federación tendrá a su cargo: I. Fiscalizar en forma posterior los ingresos, egresos y deuda...".22

Asimismo, la posterioridad se vislumbra cuando el párrafo tercero del artículo 79 (añadido por la reforma del 27 de mayo de 2015) señala que:

La Auditoría Superior de la Federación podrá iniciar el proceso de fiscalización a partir del primer día hábil del ejercicio fiscal siguiente, sin perjuicio de que las observaciones o recomendaciones que, en su caso realice, deberán referirse a la información definitiva presentada en la Cuenta Pública.

Respecto al último caso, si bien es cierto que el tercer párrafo del artículo 79 parece establecer una orden de posterioridad en la revisión de la Cuenta Pública por parte de la ASF, la cual puede activarse "a partir del primer día hábil del ejercicio fiscal siguiente" al periodo en que se ejerció el gasto, también debe admitirse que esa orden viene matizada por el párrafo inmediato subsecuente, el cual permite revisiones del ejercicio fiscal en curso. ${ }^{23}$

22 Se advierte que esa fracción fue reformada por la "reforma de la deuda pública" del 26 de mayo del 2015 y no por la "reforma de la ASF" del 27 de mayo del 2015. En tal sentido, es comprensible el error, pues la "reforma de la deuda pública" no tenía como objetivo cambiar los principios rectores de la fiscalización. Artículo 79. "La Auditoría Superior de la Federación tendrá a su cargo I. Fiscalizar en forma posterior los ingresos, egresos y deuda; las garantías que, en su caso, otorgue el gobierno federal respecto a empréstitos de los estados y municipios; el manejo, la custodia y la aplicación de fondos y recursos de los poderes de la Unión y de los entes públicos federales, así como realizar auditorías sobre el desempeño en el cumplimiento de los objetivos contenidos en los programas federales, a través de los informes que se rendirán en los términos que disponga la Ley. Párrafo reformado Diario Oficial de la Federación, 26 de mayo de 2015” (resaltado añadido).

23 Artículo 79. "Asimismo, por lo que corresponde a los trabajos de planeación de las 
Por otro lado, a pesar de que la reforma del 27 de mayo de 2015 ahora permite a la ASF revisar la Cuenta Pública de manera multianual, podría argumentarse que el principio de anualidad aún sigue vigente, a pesar de haber sido eliminado del texto del artículo 79. Esto se desprende de la lectura del artículo 79 fracción I en su cuarto párrafo, el cual a pesar de permitir la revisión multianual, aclara que los efectos jurídicos de esa revisión sólo pueden circunscribirse a la revisión de la Cuenta Pública del año que se está revisando. ${ }^{24}$ En otras palabras, el artículo 79 fracción I en su cuarto párrafo permite revisiones multianuales sin efectos jurídicos.

No obstante lo anterior, el siguiente párrafo de ese mismo artículo permite a la ASF realizar revisiones de la Cuenta Pública de carácter multianual, con los efectos jurídicos que disponga la ley. También permite revisiones del ejercicio fiscal en curso, con los efectos jurídicos que disponga la ley. Así, en este párrafo constitucional parece no aplicar el principio de anualidad y posterioridad. ${ }^{25}$

auditorías, la Auditoría Superior de la Federación podrá solicitar información del ejercicio en curso, respecto de procesos concluidos".

24 Artículo 79. La Auditoría Superior de la Federación tendrá a su cargo: I...

Cuarto párrafo. La Auditoría Superior de la Federación podrá solicitar y revisar, de manera casuística y concreta, información de ejercicios anteriores al de la Cuenta Pública en revisión, sin que por este motivo se entienda, para todos los efectos legales, abierta nuevamente la Cuenta Pública del ejercicio al que pertenece la información solicitada, exclusivamente cuando el programa, proyecto o la erogación, contenidos en el presupuesto en revisión abarque para su ejecución y pago diversos ejercicios fiscales $O$ se trate de revisiones sobre el cumplimiento de los objetivos de los programas federales. Las observaciones y recomendaciones que, respectivamente, la Auditoría Superior de la Federación emita, sólo podrán referirse al ejercicio de los recursos públicos de la Cuenta Pública en revisión. Énfasis añadido.

25 Artículo 79. La Auditoría Superior de la Federación tendrá a su cargo: I...

Quinto párrafo. "Sin perjuicio de lo previsto en el párrafo anterior, en las situaciones que determine la Ley, derivado de denuncias, la Auditoría Superior de la Federación, previa autorización de su titular, podrá revisar durante el ejercicio fiscal en curso a las entidades fiscalizadas, así como respecto de ejercicios anteriores. Las entidades fiscalizadas proporcionarán la información que se solicite para la revisión, en los plazos y términos señalados por la Ley y, en caso de incumplimiento, serán aplicables las sanciones previstas en la misma. La Auditoría Superior de la Federación rendirá un informe específico a la Cámara de Diputados y, en su caso, promoverá las acciones que correspondan ante el Tribunal Federal de Justicia Administrativa, la Fiscalía Especializada en Combate a la Corrupción o las autoridades competentes”. Énfasis añadido. 
Entonces, lo que arroja el estudio del texto constitucional reformado es que existen supuestos jurídicos en los que parece aplicar la posterioridad y la anualidad, y existen otros supuestos jurídicos en los que no aplican, como se refleja en la siguiente tabla:

\section{Tabla 1. Supuestos jurídicos en los que aplica y no aplica la posteriori- dad y la anualidad en el artículo 79 constitucional}

\begin{tabular}{|c|c|}
\hline $\begin{array}{l}\text { Segundo } \\
\text { párrafo: }\end{array}$ & $\begin{array}{l}\text { Establece los principios rectores de la actividad de fiscalización de la ASF } \\
\text { y la reforma del Diario Oficial de la Federación, } 27 \text { de mayo de } 2015 \\
\text { elimina los principios de posterioridad y anualidad. }\end{array}$ \\
\hline $\begin{array}{l}\text { Tercer } \\
\text { párrafo: }\end{array}$ & $\begin{array}{l}\text { Este nuevo párrafo establece que la ASF puede comenzar a revisar desde } \\
\text { el } 2 \text { de enero (o el siguiente día hábil) la Cuenta Pública del año anterior, } \\
\text { pero sus informes sólo podrán basarse en la información que presente la } \\
\text { SHCP en la Cuenta Pública definitiva (lo cual sucede a más tardar el } 30 \text { de } \\
\text { abril, de acuerdo al artículo } 74 \text { fracc. VI). Entonces, de acuerdo a este tercer } \\
\text { párrafo, a la ASF se le permite del } 2 \text { de enero al } 30 \text { de abril revisar, pero } \\
\text { no informar. Sólo después del } 30 \text { de abril se le permite también informar. } \\
\text { De esta forma, este párrafo implica anualidad y una doble posterioridad, } \\
\text { puesto que se establece que la ASF puede comenzar a revisar la Cuenta } \\
\text { Pública del año anterior, después de que termine el año fiscal, a partir del } \\
2 \text { de enero siguiente. La segunda posterioridad la marca el } 30 \text { de abril para } \\
\text { poder revisar e informar. }\end{array}$ \\
\hline $\begin{array}{l}\text { Cuarto } \\
\text { párrafo: }\end{array}$ & $\begin{array}{l}\text { Permite a la ASF solicitar información del año en curso, sobre procesos } \\
\text { terminados. Por ejemplo, la ASF puede solicitar información sobre un } \\
\text { contrato público pagado en su totalidad antes de que termine el ejercicio } \\
\text { fiscal en curso. Sin embargo, aplican las mismas salvedades del párrafo } \\
\text { anterior, en relación a que no puede emitir informes u observaciones res- } \\
\text { pecto de gastos que no estén reflejados en la Cuenta Pública definitiva. }\end{array}$ \\
\hline $\begin{array}{l}\text { Fracc. I: } \\
\text { Cuarto } \\
\text { párrafo: }\end{array}$ & $\begin{array}{l}\text { Permite a la ASF realizar retrorrevisiones* multianuales a la Cuenta Pú- } \\
\text { blica, pero sin efectos jurídicos. }\end{array}$ \\
\hline $\begin{array}{l}\text { Quinto } \\
\text { párrafo }\end{array}$ & $\begin{array}{l}\text { Permite a la ASF realizar retrorrevisiones multianuales a la Cuenta Pública, } \\
\text { con los efectos jurídicos que disponga la ley. También permite revisiones } \\
\text { del ejercicio fiscal en curso, con los efectos jurídicos que disponga la ley. } \\
\text { En ambos casos, se necesita autorización del titular de la ASF para co- } \\
\text { menzar las revisiones respectivas. }\end{array}$ \\
\hline
\end{tabular}

* Para una explicación del concepto "retrorrevisión", véase la siguiente sección de este documento.

Ante esta diversidad de escenarios, vale la pena preguntarse si la fiscalización sigue estando regida por los principios de anualidad y posterioridad. Mi respuesta es que no, pues es innegable el hecho de que esas palabras 
fueron eliminadas del texto del artículo 79 constitucional en su párrafo segundo por "la reforma de la ASF", además de otros lugares del artículo 79, así como de los artículos 116 y 122 constitucionales. ${ }^{26}$ Esta interpretación se confirma con la lectura de la exposición de motivos de "la reforma de la ASF" (la cual será retomada en la siguiente sección). ${ }^{27}$

Al confrontar esta postura con las posibles incosistencias presentadas entre el texto del párrafo tercero y cuarto del artículo 79, puedo concluir que no existe una contradicción, puesto que una lectura armónica de ambos párrafos con el resto del texto del artículo 79 permite ver que la ASF no necesita esperar a que termine el año fiscal para solicitar información del año en curso.

Sin embargo, la fracción I del párrafo 5o. del artículo 79, en mi opinión sí refleja una inconsistencia con el espíritu de la reforma que eliminó el principio de posterioridad de los principios rectores de la ASF. Esto es así porque la parte aludida del texto del artículo 79 sigue estableciendo expresamente que la ASF actuará "en forma posterior". Por esta razón, se propone una reforma al artículo 79 constitucional para que se elimine la frase "en forma posterior" de la fracción I del pfo. 5o. del artículo 79 que actualmente señala que "La Auditoría Superior de la Federación tendrá a su cargo: I. Fiscalizar en forma posterior los ingresos, egresos y deuda...".

Por último, respecto a la posible contradicción encontrada con la vigencia del principio de anualidad, teniendo en cuenta los artículos citados y la exposición de motivos de la "reforma de la ASF" del 27 de mayo de 2015, debo admitir que la contradicción puede salvarse con una interpretación teleológica de la reforma del 27 de mayo, y por lo tanto no existe contradicción con el párrafo tercero del artículo 79.

\section{AlCANCE “RETRORREVISOR” DE LA FUNCIÓN FISCALIZADORA}

Retomando el tema que quedó pendiente en la sección anterior, decíamos que la eliminación del principio de anualidad del texto de los artículos 79, 116 y 122 constitucionales permite ahora a la ASF revisar ejercicios anteriores al que constituye la materia de la verificación. Ante este nuevo escenario,

\footnotetext{
26 Véase la nota 19 de este documento.

27 Declaratoria de publicidad de los dictámenes de la Comisión de Puntos Constitucionales, con proyecto de decreto por el que se reforman y adicionan diversas disposiciones de la Constitución Política de los Estados Unidos Mexicanos, en materia de anticorrupción, cit.
} 
cabe preguntarse si existe un límite para esta revisión retroactiva, o si se me permite el término, si existe un límite para esta "retrorrevisión".

Sobre este punto, en la exposición de motivos de la "reforma de la ASF" se menciona que se propuso modificar el ordenamiento constitucional en materia de fiscalización para "Eliminar los principios de posterioridad y de anualidad para que la ASF pueda fiscalizar hasta tres ejercicios anteriores y el que esté en curso (tiempo real)". ${ }^{28}$ Si bien esto no forma parte del texto constitucional, la exposición de motivos sí puede ser utilizada por la SCJN para aclarar una controversia sobre el significado del texto constitucional. Por esta razón, se genera la duda de ¿cuál es el alcance "retrorrevisor" de la función fiscalizadora? ¿Tres años, como indica la exposición de motivos? O bien, ¿sin límite alguno, pues el texto constitucional no impone límites?

Ciertamente, la Ley de Fiscalización y Rendición de Cuentas de la Federación no impone ningún límite, por lo que actualmente no parece haber una controversia. No obstante, la referencia temporal de tres años plasmada en la exposición de motivos de la "reforma de la ASF" genera una duda razonable al respecto, especialmente en el caso de que el Congreso federal o alguno de los locales, cambiara su ley respectiva para imponer un límite al alcance "retrorrevisor" de la entidad fiscalizadora correspondiente.

Por esta razón, se recomienda una reforma constitucional que aclare expresamente que no existen límites temporales en la fiscalización federal ni estatal o, en su caso, especifique un número de años. Esto brindará certidumbre jurídica tanto a entes fiscalizados como a fiscalizadores, y evitará potenciales controversias constitucionales.

\section{CONCLUSIONES}

Tanto la "reforma constitucional de la deuda pública" como la "reforma constitucional de la ASF" contribuyen al fortalecimiento del Sistema Nacional Anticorrupción. Ambas apuntan en la dirección correcta, pero han dejado en su camino inconsistencias importantes respecto los principios jurídicos que regirán la labor fiscalizadora de la ASF y de las entidades de fiscalización estatales y de la Ciudad de México.

Actualmente los textos de los artículos 79, 116 y 122 contienen contradicciones que pueden complicar o entorpecer la fiscalización de recursos públi-

\footnotetext{
28 Ibidem, pp. 20 y 46.
} 
cos. Es necesario tener claridad jurídica sobre este tema. Por esta razón, se proponen tres reformas a la Constitución que le darían coherencia y balance, y sobre todo otorgaría certidumbre jurídica a entes fiscalizados y fiscalizadores. En resumen, se presentan dichas propuestas de reforma a continuación.

La primera propuesta de reforma constitucional está relacionada con el desbalance que existe con el principio de definitividad. Como se demostró, es contrastante la ausencia del principio de definitividad para la fiscalización a nivel local, porque la Constitución no lo exige para las entidades estatales de fiscalización (artículo 116) ni para la Ciudad de México (artículo 122), pero sí lo exige a nivel federal (artículo 79). Por esta razón, se recomienda una reforma constitucional que equilibre la asimetría existente entre por un lado el artículo 79 y, por otro lado, los artículos 116 y 122.

La segunda propuesta de reforma constitucional está relacionada con la inconsistencia del principio de posterioridad. Como se explicó, este principio fue eliminado del segundo párrafo del artículo 79, el cual enlista los principios jurídicos que regirán la labor fiscalizadora de la ASF. Sin embargo, sigue existiendo una alusión a dicho principio en el mismo texto del artículo 79. Por esta razón, se propone una reforma al artículo 79 constitucional para que se elimine la frase "en forma posterior" de la fracción I del párrafo quinto del artículo 79 que actualmente señala que "La Auditoría Superior de la Federación tendrá a su cargo: I. Fiscalizar posterior los ingresos, egresos y deuda...".

La tercera propuesta de reforma constitucional busca aclarar el alcance "retrorrevisor" de la función fiscalizadora. Actualmente dicho alcance no está determinado por el artículo 79 de la Constitución. Sin embargo, como consecuencia de la "reforma de las ASF" que eliminó el principio de posterioridad y el principio de anualidad, en el curso de los debates legislativos se presentaron argumentos que sí dejan ver una intención para delimitar el alcance retroactivo de la función fiscalizadora. Por esta razón, se recomienda una reforma constitucional que aclare que no existen límites temporales en la fiscalización federal ni estatal o, en su caso, especifique un número de años determinado. 
Tabla 2. Matriz histórica (abreviada) de los artículos 79,116 y 122 constitucionales*

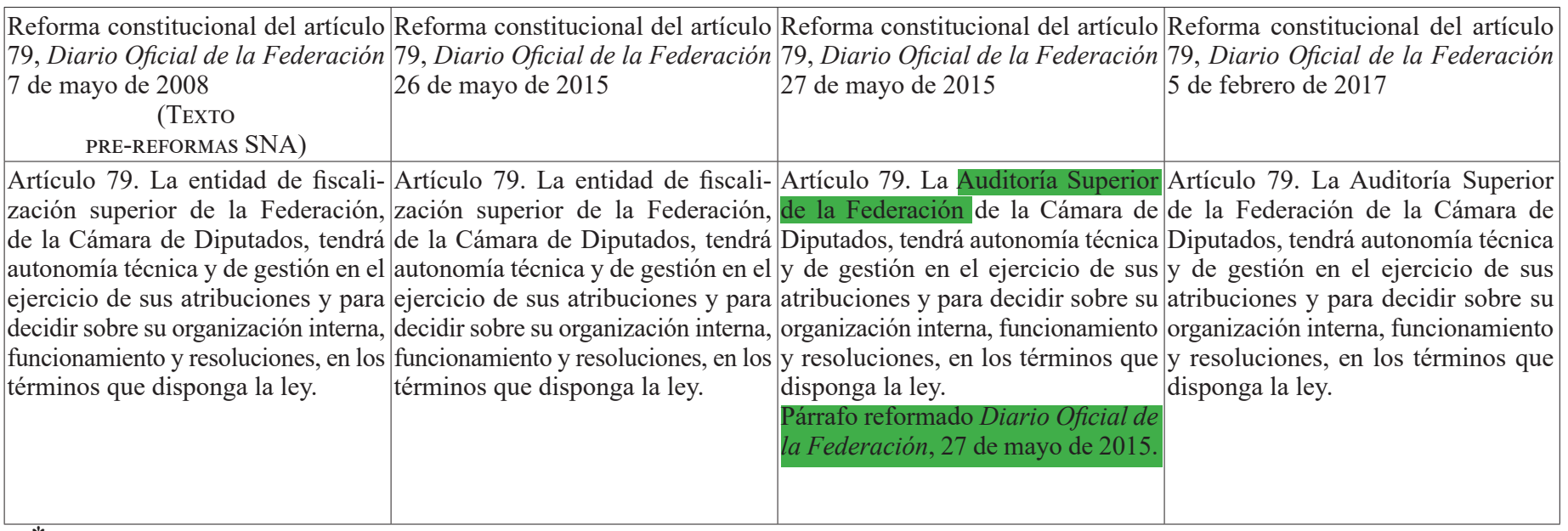

* Instrucciones para su lectura: para el caso de poder leer esta tabla en formato de color, en la segunda columna de izquierda a derecha, se resaltan en color amarillo los cambios entre la última reforma previa al Sistema Nacional Anticorrupción del 7 de mayo de 2008 y la reforma del 26 de mayo de 2015. En la tercera columna de izquierda a derecha, se resaltan en color verde los cambios entre la reforma del 26 y la del 27 de mayo de 2015. En la cuarta columna, es decir la última columna del lado derecho, se resaltan en color azul turquesa los cambios entre la reforma del 27 de mayo de 2015 y la del 5 de febrero de 2017. El texto tachado también es añadido, e indica que esa parte sería eliminado por la reforma del 27 de mayo de 2015. En todas las columnas, se pone en negritas cualquier referencia expresa a los principios de posterioridad, anualidad, legalidad, definitividad, imparcialidad y confiabilidad. Si estos principios no están resaltados, esto significa que no fueron modificados por la reforma que corresponde a esa columna. 
La función de fiscalización será La función de fiscalización será La función de fiscalización será La función de fiscalización será ejerejercida conforme a los principios ejercida conforme a los principios ejercida conforme a los principios cida conforme a los principios de lede posterioridad, anualidad, lega- de posterioridad, anualidad, lega- de posterioridad, antuatidatt, lega- galidad, definitividad, imparcialidad lidad, definitividad, imparcialidad lidad, definitividad, imparcialidad lidad, definitividad, imparcialidad y confiabilidad.

\section{y confiabilidad. \\ y confiabilidad. \\ y confiabilidad.}

Párrafo adicionado Diario Oficial de Esta entidad de fiscalización superior la Federación, 7 de mayo de 2008. de la Federación tendrá a su cargo: Esta entidad de fiscalización superior I. Fiscalizar en forma posterior los de la Federación tendrá a su cargo: ingresos, egresos y deuda; las garantías I. Fiscalizar en forma posterior los que, en su caso, otorgue el Gobierno ingresos y egresos; el manejo, la Federal respecto a empréstitos de los custodia y la aplicación de fondos y Estados y Municipios; el manejo, la recursos de los Poderes de la Unión custodia y la aplicación de fondos y y de los entes públicos federales, recursos de los Poderes de la Unión así como realizar auditorías sobre el y de los entes públicos federales, desempeño en el cumplimiento de los así como realizar auditorías sobre el objetivos contenidos en los programas desempeño en el cumplimiento de los federales, a través de los informes objetivos contenidos en los programas que se rendirán en los términos que federales, a través de los informes disponga la Ley. que se rendirán en los términos que También fiscalizará directamente los disponga la Ley.

recursos federales que administren o Párrafo reformado Diario Oficial de ejerzan los estados, los municipios, el la Federación, 26 de mayo de 2015 Distrito Federal y los órganos político- También fiscalizará directamente los administrativos de sus demarcaciones recursos federales que administren o territoriales, con excepción de las ejerzan los Estados, los Municipios, el participaciones federales; asimismo, Distrito Federal y los órganos políticoadministrativos de sus demarcaciones territoriales, con excepción de las

\section{Reformado Diario Oficial de la $F$}

deración, 27 de mayo de 2015.

La Auditoría Superior de la Fede-

ración podrá iniciar el proceso de fiscalización a partir del primer día hábil del ejercicio fiscal siguiente, sin perjuicio de que las observaciones o recomendaciones que, en su caso realice, deberán referirse a la información definitiva presentada en la Cuenta Pública.

Párrafo adicionado Diario Oficial de la Federación, 27 de mayo de 2015 Asimismo, por lo que corresponde a los trabajos de planeación de las auditorías, la Auditoría Superior de la Federación podrá solicitar información del ejercicio en curso, respecto de procesos concluidos.

Párrafo adicionado Diario Oficial de la Federación, 27 de mayo de 2015. La Auditoría Superior de la Federación podrá iniciar el proceso de fiscalización a partir del primer día hábil del ejercicio fiscal siguiente, sin perjuicio de que las observaciones o recomendaciones que, en su caso realice, deberán referirse a la información definitiva presentada en la Cuenta Pública.

Asimismo, por lo que corresponde a los trabajos de planeación de las auditorías, la Auditoría Superior de la Federación podrá solicitar información del ejercicio en curso, respecto de procesos concluidos.

La Auditoría Superior de la Federación tendrá a su cargo:

I. Fiscalizar en forma posterior los ingresos, egresos y deuda; las garantías que, en su caso, otorgue el Gobierno Federal respecto a empréstitos de los Estados y Municipios; el manejo, la custodia y la aplicación de fondos y recursos de los Poderes de la Unión y de los entes públicos federales, así 
fiscalizará los recursos federales que participaciones federales. En el caso La Auditoría Superior de la Federase destinen y se ejerzan por cualquier de los Estados y los Municipios ción tendrá a su cargo: entidad, persona física o moral, pública cuyos empréstitos cuenten con la Párrafo reformado Diario Oficial de o privada, y los transferidos a fideico- garantía de la Federación, fiscalizará la Federación, 27 de mayo de 2015. misos, mandatos, fondos o cualquier el destino y ejercicio de los recursos I. Fiscalizar en forma posterior los otra figura jurídica, de conformidad correspondientes que hayan realiza- ingrc con los procedimientos establecidos do los gobiernos locales. Asimismo, que, en su caso, otorgue el Gobierno También fiscalizará directamente los en las leyes y sin perjuicio de la fiscalizará los recursos federales que Federal respecto a empréstitos de los recursos federales que administren competencia de otras autoridades y se destinen y se ejerzan por cualquier Estados y Municipios; el manejo, la o ejerzan las entidades federativas de los derechos de los usuarios del entidad, persona física o moral, pública custodia y la aplicación de fondos y los municipios y las demarcaciones sistema financiero.

$\cdots$ o privada, y los transferidos a fideico- recursos de los Poderes de la Unión territoriales de la Ciudad de México misos, mandatos, fondos o cualquier y de los entes públicos federales, En los términos que establezca la ley Sin perjuicio del principio de anua- otra figura jurídica, de conformidad así como realizar auditorías sobre el fiscalizará, en coordinación con las lidad, la entidad de fiscalización con los procedimientos establecidos desempeño en el cumplimiento de los entidades locales de fiscalización o superior de la Federación podrá en las leyes y sin perjuicio de la objetivos contenidos en los programas de manera directa, las participaciones solicitar y revisar, de manera ca- competencia de otras autoridades y federales, a través de los informes federales. En el caso de los Estados suística y concreta, información de de los derechos de los usuarios del que se rendirán en los términos que y los Municipios cuyos empréstitos ejercicios anteriores al de la Cuenta sistema financiero. disponga la Ley. cuenten con la garantía de la FederaPública en revisión, sin que por este Párrafo reformado Diario Oficial de También fiscalizará directamente los ción, fiscalizará el destino y ejercicio motivo se entienda, para todos los la Federación, 26 de mayo de 2015 recursos federales que administren o de los recursos correspondientes que efectos legales, abierta nuevamente $\ldots$ la Cuenta Pública del ejercicio al que Sin perjuicio del principio de anua- el Distrito Federal y los órganos Asimismo, fiscalizará los recursos pertenece la información solicitada, lidad, la entidad de fiscalización político-administrativos de sus demar- federales que se destinen y se ejerexclusivamente cuando el programa, superior de la Federación podrá so- caciones territoriales eon exeepeión zan por cualquier entidad, persona proyecto o la erogación, contenidos licitar y revisar, de manera casuística de las partieipaeiones federales. En física o moral, pública o privada, y en el presupuesto en revisión abarque y concreta, información de ejercicios los términos que establezca la ley los transferidos a fideicomisos, fonpara su ejecución y pago diversos anteriores al de la Cuenta Pública fiscalizará, en coordinación con las dos y mandatos, públicos o privados, ejercicios fiscales o se trate de revi- en revisión, sin que por este motivo entidades locales de fiscalización o o cualquier otra figura jurídica, de siones sobre el cumplimiento de los se entienda, para todos los efectos de manera directa, las participacio- conformidad con los procedimientos 
objetivos de los programas federales. legales, abierta nuevamente la Cuenta nes federales. En el caso de los Estados establecidos en las leyes y sin perjuicio Las observaciones y recomendaciones Pública del ejercicio al que pertenece y los Municipios cuyos empréstitos de la competencia de otras autoridades que, respectivamente, la entidad de la información solicitada, exclusiva- cuenten con la garantía de la Federa- y de los derechos de los usuarios del fiscalización superior de la Federa- mente cuando el programa, proyecto ción, fiscalizará el destino y ejercicio sistema financiero.

ción emita, sólo podrán referirse al o la erogación, contenidos en el pre- de los recursos correspondientes que Párrafo reformado 29 de enero de 2016. ejercicio de los recursos públicos de supuesto en revisión abarque para su hayan realizado los gobiernos locales. la Cuenta Pública en revisión. ejecución y pago diversos ejercicios Asimismo, fiscalizará los recursos Asimismo, sin perjuicio del principio fiscales o se trate de revisiones sobre federales que se destinen y se ejerzan de posterioridad, en las situacio- el cumplimiento de los objetivos por cualquier entidad, persona físines excepcionales que determine la de los programas federales. Las ca o moral, pública o privada, y los Ley, derivado de denuncias, podrá observaciones y recomendaciones transferidos a fideicomisos, fondos requerir a las entidades fiscalizadas que, respectivamente, la entidad de y mandatos, públicos y privados, que procedan a la revisión, durante fiscalización superior de la Federa- o cualquier otra figura jurídica, de el ejercicio fiscal en curso, de los ción emita, sólo podrán referirse al conformidad con los procedimientos conceptos denunciados y le rindan ejercicio de los recursos públicos de establecidos en las leyes y sin perjuicio un informe. Si estos requerimientos la Cuenta Pública en revisión. de la competencia de otras autoridades no fueren atendidos en los plazos y Asimismo, sin perjuicio del principio y de los derechos de los usuarios del formas señalados por la Ley, se im- de posterioridad, en las situacio- sistema financiero.

pondrán las sanciones previstas en la nes excepcionales que determine la Párrafo reformado 27 de mayo de misma. La entidad de fiscalización Ley, derivado de denuncias, podrá 2015, superior de la Federación rendirá un requerir a las entidades fiscalizadas ... informe específico a la Cámara de que procedan a la revisión, durante Sinperjuieiodel prineipio de antraDiputados y, en su caso, fincará las el ejercicio fiscal en curso, de los lidat, La Auditoría Superior de de la responsabilidades correspondientes conceptos denunciados y le rindan Federación podrá solicitar y revisar, o promoverá otras responsabilidades un informe. Si estos requerimientos de manera casuística y concreta, inante las autoridades competentes; no fueren atendidos en los plazos y formación de ejercicios anteriores Fracción reformada Diario Oficial de formas señalados por la Ley, se im- al de la Cuenta Pública en revisión, la Federación, 7 de mayo de 2008. pondrán las sanciones previstas en la sin que por este motivo se entienda misma. La entidad de fiscalización para todos los efectos legales, abierta, 
II. Entregar el informe del resultado superior de la Federación rendirá un $\mid$ nuevamente la Cuenta Pública del $\ldots$

de la revisión de la Cuenta Pública a informe específico a la Cámara de ejercicio al que pertenece la infor- La Auditoría Superior de la Federación la Cámara de Diputados a más tardar Diputados y, en su caso, fincará las mación solicitada, exclusivamente podrá solicitar y revisar, de manera el 20 de febrero del año siguiente al de responsabilidades correspondientes cuando el programa, proyecto o la casuística y concreta, información de su presentación, el cual se someterá o promoverá otras responsabilidades erogación, contenidos en el presu- ejercicios anteriores al de la Cuenta a la consideración del pleno de dicha ante las autoridades competentes; puesto en revisión abarque para su Pública en revisión, sin que por este Cámara y tendrá carácter público. II. Entregar el informe del resultado ejecución y pago diversos ejercicios motivo se entienda, para todos los Dentro de dicho informe se incluirán de la revisión de la Cuenta Pública a fiscales o se trate de revisiones sobre efectos legales, abierta nuevamente las auditorías practicadas, los dictá- la Cámara de Diputados a más tardar el cumplimiento de los objetivos la Cuenta Pública del ejercicio al que menes de su revisión, los apartados el 20 de febrero del año siguiente al de de los programas federales. Las pertenece la información solicitada, correspondientes a la fiscalización del su presentación, el cual se someterá observaciones y recomendaciones exclusivamente cuando el programa, manejo de los recursos federales por a la consideración del pleno de dicha que, respectivamente, la Auditoría proyecto o la erogación, contenidos parte de las entidades fiscalizadas a Cámara y tendrá carácter público. Superior de la Federación emita, en el presupuesto en revisión abarque que se refiere la fracción anterior y Dentro de dicho informe se incluirán sólo podrán referirse al ejercicio de para su ejecución y pago diversos a la verificación del desempeño en las auditorías practicadas, los dictá- los recursos públicos de la Cuenta ejercicios fiscales o se trate de reviel cumplimiento de los objetivos de menes de su revisión, los apartados Pública en revisión.

los programas federales, así como correspondientes a la fiscalización del Párrafo reformado Diario Oficial de también un apartado específico con manejo de los recursos federales por la Federación, 27 de mayo de 2015, las observaciones de la entidad de parte de las entidades fiscalizadas a ... siones sobre el cumplimiento de los fiscalización superior de la Federa- que se refiere la fracción anterior y S ción que incluya las justificaciones a la verificación del desempeño en y aclaraciones que, en su caso, las el cumplimiento de los objetivos de entidades fiscalizadas hayan presen- los programas federales, así como tado sobre las mismas.

también un apartado específico con Para tal efecto, de manera previa las observaciones de la entidad de a la presentación del informe del fiscalización superior de la Federaresultado se darán a conocer a las ción que incluya las justificaciones

Sin perjuicio te

rioritlat de lo previsto en el párrafo anterior, en las situaciones exeepeioque determine la Ley, derivado Pública en revisión.

de denuncias, la Auditoría Superior objetivos de los programas federales. Las observaciones y recomendaciones que, respectivamente, la Auditoría Superior de la Federación emita, sólo podrán referirse al ejercicio de los recursos públicos de la Cuenta entidades fiscalizadas la parte que y aclaraciones que, en su caso, las les corresponda de los resultados de entidades fiscalizadas hayan presen- 
su revisión, a efecto de que és- tado sobre las mismas. tas presenten las justificaciones y Para tal efecto, de manera previa aclaraciones que correspondan, las a la presentación del informe del cuales deberán ser valoradas por la resultado se darán a conocer a las entidad de fiscalización superior de entidades fiscalizadas la parte que la Federación para la elaboración del les corresponda de los resultados informe del resultado de la revisión de su revisión, a efecto de que ésde la Cuenta Pública.

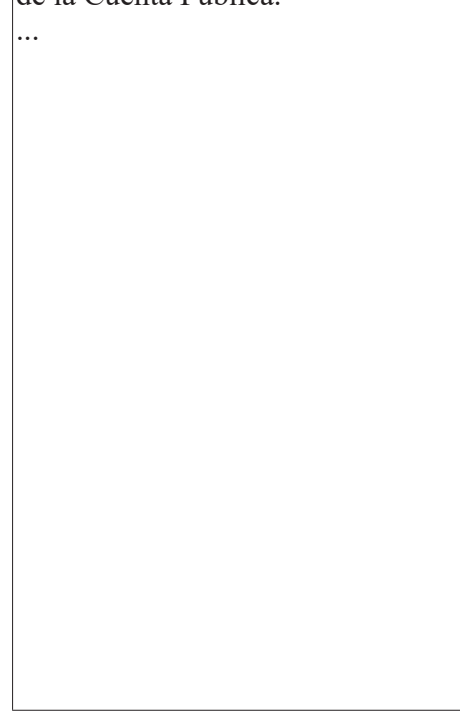
informe del resultado de la revisión de la Cuenta Pública. ... tas presenten las justificaciones y específico a la Cámara de Diputados dades fiscalizadas, así como respecto
aclaraciones que correspondan, las y, en su caso, promoverá las acciones de ejercicios anteriores. Las entidades cuales deberán ser valoradas por la que correspondan ante el Tribunal fiscalizadas proporcionarán la inforentidad de fiscalización superior de Federal de Justicia Administrativa, mación que se solicite para la revisión, la Federación para la elaboración del la Fiscalía Especializada en Combate en los plazos y términos señalados por

BJV, Instituto de Investigaciones Jurídicas-UNAM, 2017

https://revistas.juridicas.unam.mx/index.php/cuestiones-constitucionales/issue/archive fiscalizadas proporcionarán la infor-

mación que se solicite para la revisión, en los plazos y términos señalados por a Ley y, en caso de incumplimiento, erán aplicables las sanciones previstas la misma. La Auditoría Superior de su Titular, podrá revisar durante de la Federación rendirá un informe el ejercicio fiscal en curso a las enti-

Sin perjuicio de lo previsto en el párrafo anterior, en las situaciones que determine la Ley, derivado de denuncias, la Auditoría Superior de a la Corrupción o las autoridades competentes; II. Entregar a la Cámara de Dipu- específico a la Cámara de Diputados tados, el último día hábil de los y, en su caso, promoverá las acciones meses de junio y octubre, así como que correspondan ante el Tribunal el 20 de febrero del año siguiente Federal de Justicia Administrativa, al de la presentación de la Cuenta la Fiscalía Especializada en CombaPública, los informes individuales te a la Corrupción o las autoridades de auditoría que concluya durante competentes;

el periodo respectivo. Asimismo, en II. Entregar a la Cámara de Diputaesta última fecha, entregar el Informe dos, el último día hábil de los meses General Ejecutivo del Resultado de la de junio y octubre, así como el 20 Fiscalización Superior de la Cuenta de febrero del año siguiente al de la Pública, el cual se someterá a la con- presentación de la Cuenta Pública, los 


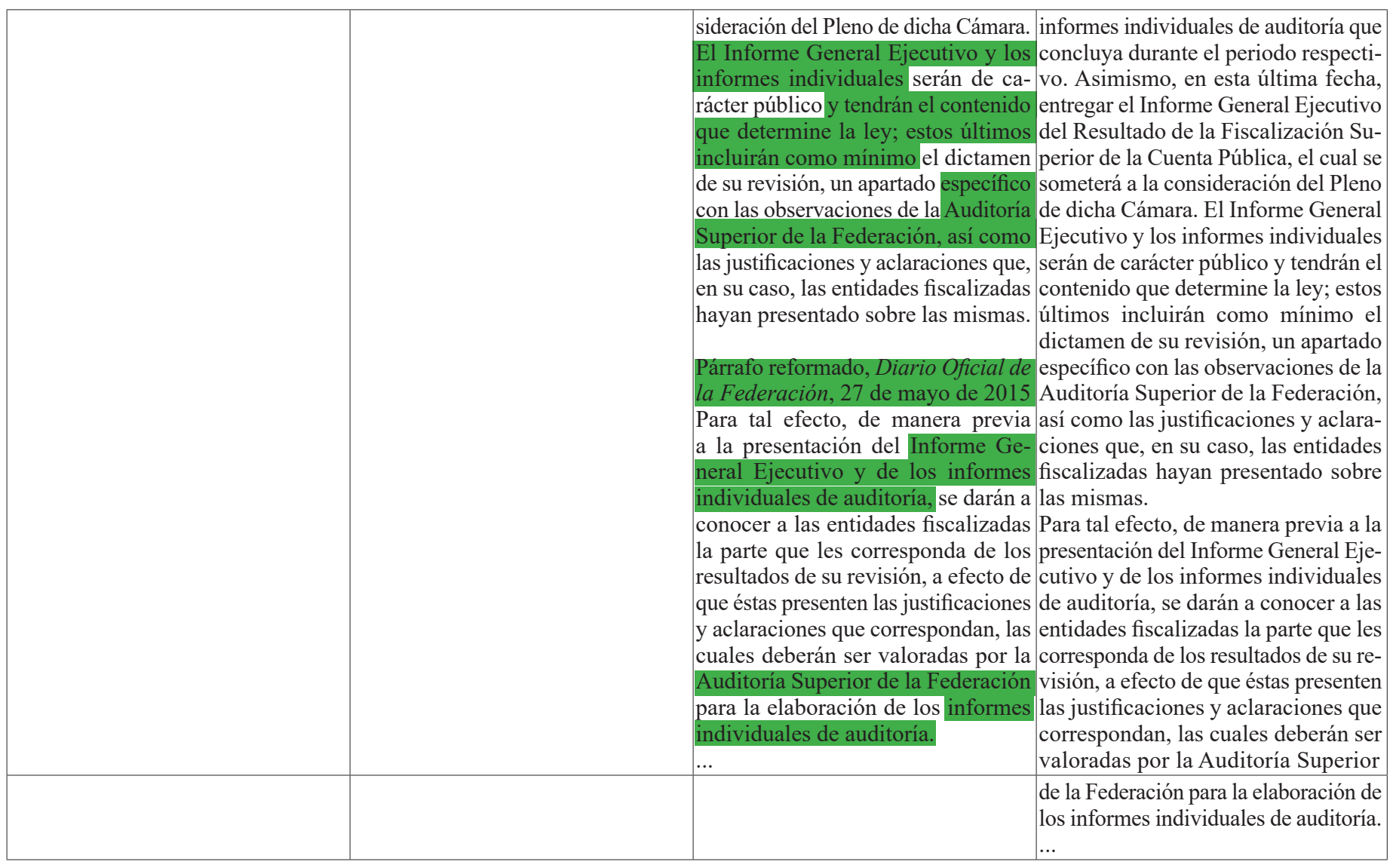

BJV, Instituto de Investigaciones Jurídicas-UNAM, 2017 


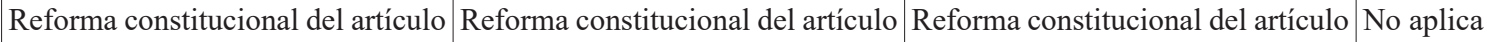 \\ 116, Diario Oficial de la Federación, 116, Diario Oficial de la Federación, 116, Diario Oficial de la Federación, \\ 7 de mayo de 2008 \\ 26 de mayo de 2015 \\ 27 de mayo de 2015 \\ (TEXTO PRE-REFORMAS SNA)}

Artículo 116. El poder público de los Artículo 116. El poder público de los Artículo 116. El poder público de los La reforma constitucional del 05 de

estados se dividirá, para su ejercicio, estados se dividirá, para su ejercicio, estados se dividirá, para su ejercicio, febrero de 2017 no cambió ninguna

en Ejecutivo, Legislativo y Judicial, en Ejecutivo, Legislativo y Judicial, en Ejecutivo, Legislativo y Judicial, palabra del artículo 116.

y no podrán reunirse dos o más de y no podrán reunirse dos o más de y no podrán reunirse dos o más de

estos poderes en una sola persona o estos poderes en una sola persona o estos poderes en una sola persona o

corporación, ni depositarse el Legis- corporación, ni depositarse el Legis- corporación, ni depositarse el Legis-

\begin{tabular}{l|l} 
lativo en un solo individuo. & lativo en un solo individuo.
\end{tabular}

Los poderes de los Estados se orga- Los poderes de los Estados se orga- Los poderes de los Estados se orga-

nizarán conforme a la Constitución nizarán conforme a la Constitución nizarán conforme a la Constitución de cada uno de ellos, con sujeción de cada uno de ellos, con sujeción de cada uno de ellos, con sujeción a las siguientes normas:

a las siguientes normas:

a las siguientes normas:

I... I...

I...

\begin{tabular}{l|l|l} 
II...pfos. 1o. a 5o. sin cambios... & II...pfos. 1o. a 5o. sin cambios... & II...pfo. 1o. a 5o. sin cambios...
\end{tabular}

Las legislaturas de los estados con- Las legislaturas de los Estados Las legislaturas de los estados contarán con entidades estatales de fis- contarán con entidades estatales de tarán con entidades estatales de fiscalización, las cuales serán órganos fiscalización, las cuales serán órganos calización, las cuales serán órganos con autonomía técnica y de gestión con autonomía técnica y de gestión con autonomía técnica y de gestión en el ejercicio de sus atribuciones y en el ejercicio de sus atribuciones y en el ejercicio de sus atribuciones y para decidir sobre su organización para decidir sobre su organización para decidir sobre su organización interna, funcionamiento y resolucio- interna, funcionamiento y resolucio- interna, funcionamiento y resoluciones, en los términos que dispongan nes, en los términos que dispongan nes, en los términos que dispongan sus leyes. sus leyes.

sus leyes. 
La función de fiscalización se desa- La función de fiscalización se desa- La función de fiscalización se desarrollará conforme a los principios de rrollará conforme a los principios de rrollará conforme a los principios de posterioridad, anualidad, legalidad, posterioridad, anualidad, legalidad, posteriorittat, antratidtatt, legalidad, imparcialidad y confiabilidad. imparcialidad y confiabilidad. imparcialidad y confiabilidad. AsiEl titular de la entidad de fiscalización Asimismo, deberán fiscalizar las mismo, deberán fiscalizar las acciones de las entidades federativas será elec- acciones de Estados y Municipios en de Estados y Municipios en materia to por las dos terceras partes de los materia de fondos, recursos locales de fondos, recursos locales y deuda miembros presentes en las legislaturas y deuda pública. pública. Los informes de auditoría de

locales, por periodos no menores a Párrafo reformado Diario Oficial de las entidades estatales de fiscalización siete años y deberá contar con ex- la Federación, 26 de mayo de 2015. tendrán carácter público. periencia de cinco años en materia El titular de la entidad de fiscalización Párrafo Reformado Diario Oficial de de control, auditoría financiera y de de las entidades federativas será elec- la Federación, 27 de mayo de 2015. responsabilidades.

to por las dos terceras partes de los El titular de la entidad de fiscalización miembros presentes en las legislaturas de las entidades federativas será eleclocales, por periodos no menores a to por las dos terceras partes de los siete años y deberá contar con ex- miembros presentes en las legislaturas periencia de cinco años en materia locales, por periodos no menores a de control, auditoría financiera y de siete años y deberá contar con exresponsabilidades. periencia de cinco años en materia de control, auditoría financiera y de responsabilidades.

La cuenta pública del año anterior deberá ser enviada a la Legislatura del Estado, a más tardar el 30 de abril. Sólo se podrá ampliar el plazo de presentación cuando medie solici- 


\begin{tabular}{|l|l|l|}
\hline & & $\begin{array}{l}\text { tud del gobernador, suficientemente } \\
\text { justificada a juicio de la Legislatura. } \\
\text { Párrafo adicionado Diario Oficial de } \\
\text { la Federación, 27 de mayo de 2015. }\end{array}$ \\
\hline
\end{tabular}

Reforma constitucional del artículo No aplica

122, Diario Oficial de la Federación,

7 de mayo de 2008

(TEXTO PRE-REFORMAS SNA)

Artículo 122. Definida por el artículo La reforma constitucional del 26 de Artículo 122. Definida por el artículo 44 de este ordenamiento la naturale- mayo de 2015 no cambió ninguna 44 de este ordenamiento la naturaza jurídica del Distrito Federal, su palabra del artículo 122.

gobierno está a cargo de los Poderes

Federales y de los órganos Ejecutivo,

Legislativo y Judicial de carácter local, en los términos de este artículo. $\cdots$

BJV, Instituto de Investigaciones Jurídicas-UNAM, 2017 gobierno está a cargo de los Poderes
Reforma constitucional del artículo Reforma constitucional del artículo 122, Diario Oficial de la Federación, 122, Diario Oficial de la Federación, 27 de mayo de 2015

5 de febrero de 2017

leza jurídica del Distrito Federal, su Federales y de los órganos Ejecutivo, Legislativo y Judicial de carácter local, en los términos de este artículo.

122. La Ciudad de México autonomía en todo lo concerniente a su régimen interior y a su organización política y administrativa.

A. El gobierno de la Ciudad de México está a cargo de sus poderes locales, en los términos establecidos en la Constitución Política de la Ciudad de México, la cual se ajustará a lo dispuesto en la presente Constitución y a las bases siguientes: 


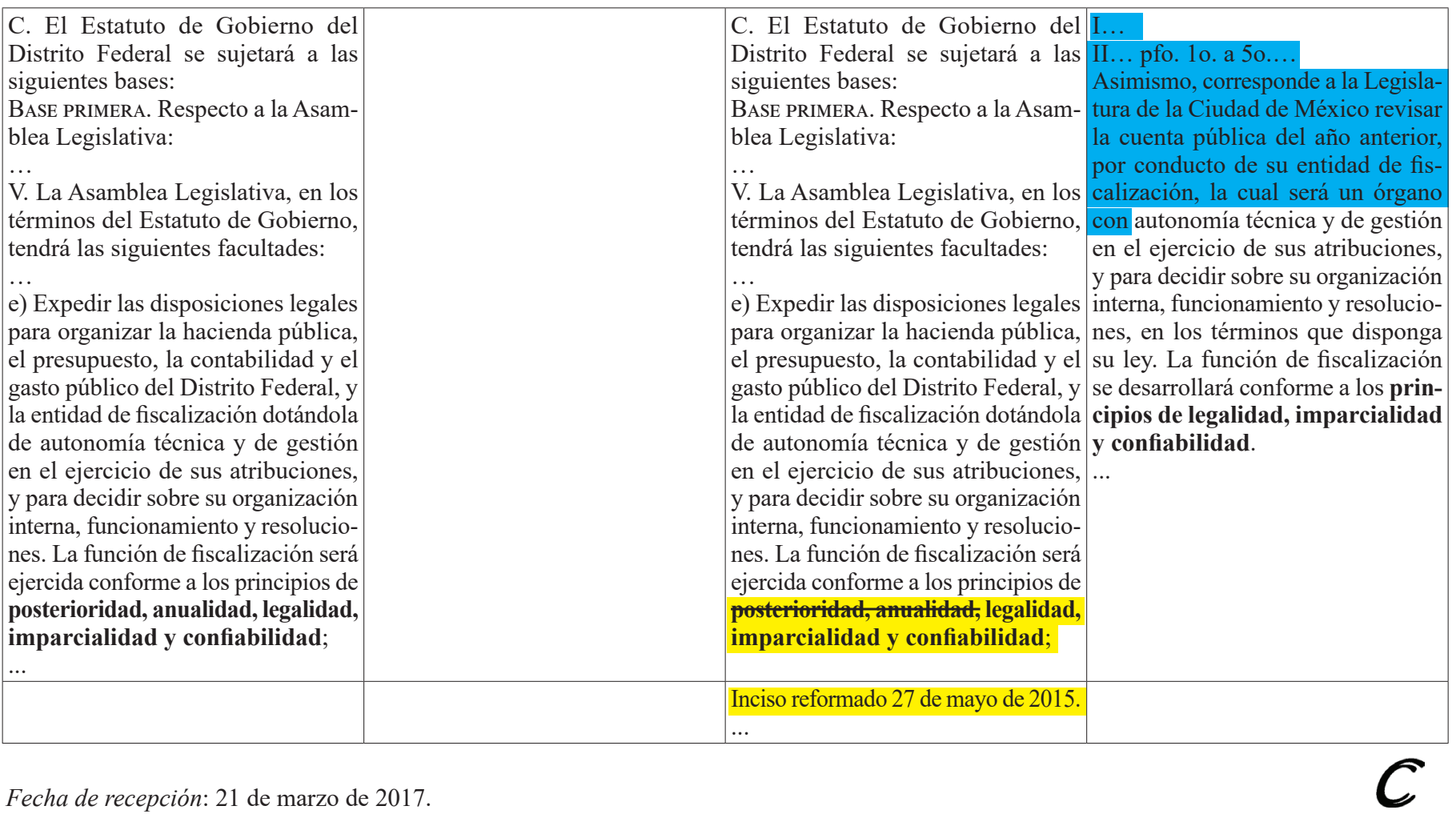

